\title{
Effect of Temperature on the Expression of I-Type Lysozyme cDNA from Oyster (Crassostrea Hongkongensis)
}

\author{
Youqing $\mathrm{Xu}^{1}$, Weijun $\mathrm{Wu}^{1}$, Zhaokun Ding ${ }^{1 *}$, Yongmei $\mathrm{Li}^{2}$, Weiming Jiang2 ${ }^{2 *}$ \\ 1 Institute for Fishery Sciences, Guangxi University, Nanning 530004, Guangxi, China; \\ 2 Guangxi Institute of Fishery Sciences, 530021 Nanning, Guangxi, China \\ * Corresponding author. Tel.: 86-7713235635; email: zhaokund@hotmail.com \\ Manuscript submitted June 1, 2016; accepted August 22, 2016. \\ doi: $10.17706 /$ ijbbb.2016.6.4.130-138
}

\begin{abstract}
An experiment was conducted to analyze thei-type lysozyme cDNA cloned from oyster (Crassostrea hongkongensis) and study the effect of temperature on the gene expression in an indoor, controlled constant-temperature environment. The cDNA was 634 bp with a 420 -bp open reading frame, encoding 139 amino acids. A new conserved amino acid sequence, HNGGPRGC, was found in the protein sequence of the i-type lysozyme from $C$. hongkongensis. Real-time quantitative PCR (RTQ-PCR) was used to assess the expression of the i-type lysozyme gene in the digestive gland, smooth muscle, gills, mantle and labial palps of $\mathrm{C}$. hongkongensis. The expression was the highest in the digestive gland and the lowest in the muscle. A thermal stress experiment was performed to study the effect of temperature on the expression of the i-type lysozyme gene. The expression was stable when water temperature ranged from $20^{\circ} \mathrm{C}$ to $25^{\circ} \mathrm{C}$. The level of expression tended to decrease at $6^{\circ} \mathrm{C}$ or $13^{\circ} \mathrm{C}$. A conclusion was drawed that the variations in temperature affect i-type lysozyme gene and immune function of $C$. hongkongensis.
\end{abstract}

Key words: I-type lysozyme, clone, expression, temperature, oyster.

\section{Introduction}

Lysozyme (EC31211117) is a ubiquitous enzyme existing in phylogenetic organisms, such as plants, invertebrate and vertebrate animals. The primary role of lysozyme is to cleave $\beta-1,4$ glycosidic bond between $\mathrm{N}$-acetylglucosamine and $\mathrm{N}$-acetylmuramic acid in the peptidoglycan of bacterial cell wall and induce cell lysis. Lysozyme is a broad-spectrum antimicrobial effector and plays an important role in the immune defense system of living organisms. The antibacterial effect of the lysozyme is particularly important for invertebrates that lack specific immunity [1]. Lysozyme is also an important digestive enzyme, decomposing microorganisms to contribute significantly as one source of $\mathrm{C}$ and $\mathrm{N}$ for the growth of invertebrate animals [2].

Lysozymes are generally classified into six different types: chicken or c-type, goose or g-type, invertebrate or i-type, phage, bacterial and plant lysozyme, in which the i-type is a lysozyme unique to invertebrate animals [3]. While invertebrate shellfish lacks a specific immune system [4]. The i-type lysozyme factors importantly in non-specific immune mechanisms, there has not been report on the cloning and expression of i-type lysozyme gene from $C$. hongkongensis [5]. Studies on the cloning, expression and structural analysis of i-type lysozyme gene would contribute to understanding the mechanism of immune defense and digestion in shellfish.

For $C$. hongkongensis in the south of China, the suitable temperature is $18-30^{\circ} \mathrm{C}$, salinity $10-20 \%$, $\mathrm{pH}$ 
7.5-8.6, dissolved oxygen over 5mg/L, light 50-500 Lux [4], [6], [7]. Crassostrea hongkongensis was threaten in summer in the south of China, resulting in serious economic loss, which was mainly attributed to increasing temperature [8]-[10]. The physiological processes of shellfish, such as feeding, growth, metabolism and mounting immune responses, vary with water temperature [7], [11] because shellfish is a cold-blooded animal and is greatly influenced by environmental temperature. Suboptimal water temperature could affect immune function and disease-resistance of shellfish, resulting in serious damage because of immune inhibition [12]-[14]. Therefore, increasing attention focuses on the effect of environmental factors, especially temperature, on the immune parameters of shellfish, such as the activities of lysozyme and antioxidant enzymes, phagocytosis, and the production of reactive oxygen species (ROS) [9]-[10], [15]. However, few studies report the effect of temperature on the expression of the i-type lysozyme gene [3].

The present paper reports the analysis of the i-type lysozyme cDNA cloned from $C$. hongkongensis and the effect of different temperatures on the expression of i-type lysozyme gene.

\section{Materials and Methods}

\subsection{Main Reagents}

Trizol reagent, Maloney marine leukemia virus (M-MLV) reverse transcription kit and platinum SYBR green qPCR supermix-UDG kit were purchased from the Invitrogen Company, USA. Gel-red dyes were purchased from Biotium Company, USA. Ordinary agarose gel DNA extraction kit (normal centrifugal columnar), $2 \times$ Taq PCR mastermix and pGM-T cloning kit were purchased from Tiangen Biochemical Technology (Beijing) Co., Ltd.

\subsection{Experimental Animal and Temperature Stress Experiment}

C. hongkongensis used for the experiment were approved by an accredited Ethics Committee of Guangxi University, Nanning City, China. Five hundred (500) C. hongkongensis (shell length $9.5-14.0 \mathrm{~cm}$, shell width 6.8-8.5cm, weight $140-256 \mathrm{~g}$ ) were purchased from Nanning free market, Guangxi province, China. The $C$. hongkongensis were firstly acclimated in aerated seawater with salinity $15 \%$, $25^{\circ} \mathrm{C}, \mathrm{pH} 8.0$, dissolved oxygen $5 \mathrm{mg} / \mathrm{L}$ and light $250 \mathrm{Lux}$ for one week in an indoor constant-temperature laboratory. Then $432 \mathrm{C}$. hongkongensis with similar sizes were selected and divided randomly into six groups of aquariums with aerated seawater with salinity 15\%, pH 8.0, density 1.06, dissolved oxygen over 5mg/L. For each group, three parallel tanks were set up and each tank was allotted randomly with $24 \mathrm{C}$. hongkongensis. The thermal stress experiments were performed on the C. hongkongensis in the 6 groups of aquariums by setting temperatures for each aquarium to $6^{\circ} \mathrm{C}, 13^{\circ} \mathrm{C}, 20^{\circ} \mathrm{C}, 27^{\circ} \mathrm{C}, 34^{\circ} \mathrm{C}$ and $25^{\circ} \mathrm{C}$ (control group), respectively. The thermal stress experiments were conducted as follows: (1) prepared seawater with desired salinity of $15 \%$, $\mathrm{pH}$ 8.0, dissolved oxygen over $5 \mathrm{mg} / \mathrm{L}$; (2) installed the seawater in all aquariums with ecosystem controller and filled oxygen to make dissolved oxygen over $5 \mathrm{mg} / \mathrm{L}$; (3) switched on the constant temperature control system for the 6 groups of aquariums and set desired temperatures to $6^{\circ} \mathrm{C}, 13^{\circ} \mathrm{C}, 20^{\circ} \mathrm{C}, 27^{\circ} \mathrm{C}, 34^{\circ} \mathrm{C}$ and $25^{\circ} \mathrm{C}$ (control group) for each experimental group, respectively; (4) the acclimated C. hongkongensis were randomly assigned into the aquariums for thermal stress experiments after the seawater temperature in each group of aquariums reached the selected temperature, which was measured by the internal thermostat of the ecosystem controller and an additional, external thermometer.

C. hongkongensis was fed using Platymonas sp. The experiment was performed for $7 \mathrm{~d}$ and sampling was at $0,1,2,3,4,5,6$, and $7 \mathrm{~d}$. From each tank, three (3) of $C$. hongkongensis were randomly selected and anaesthetized (relaxated) using $\mathrm{MgCl}_{2}(1 / 10,000)$. Five different tissues of each oyster, namely the digestive gland, smooth muscle, gills, mantle and labial palps, were excised rapidly, placed in sample tube, marked, 
weighted and frozen quickly in liquid nitrogen, and stored in $-80^{\circ} \mathrm{C}$ until analyzed.

\subsection{Total RNA Extraction}

Each tissue sample of $C$. hongkongensis was fetched from $-80^{\circ} \mathrm{C}$ and ground quickly in a mortar and pestle precooled to liquid nitrogen temperatures. Total RNA was extracted using Trizol Reagent (Invitrogen, USA), according to the method of Zheng et al. [16]. The purity and concentration of the total RNA for each sample were determined by nucleic acid protein analyzer (BIO-RAD smart spec 3000 model, USA). The integrity of the total RNA was then assessed using electrophoresis in agarose gel.

\subsection{Cloning of I-Type Lysozyme Gene from C. Hongkongensis}

The cDNA fragment of i-type lysozyme was cloned from the digestive gland of $C$. hongkongensis and the sequence was determined. The sequence was then used to amplify the first strand cDNA, which was synthesized in $20 \mu \mathrm{L}$ of reactive system using real time PCR (RT-PCR) and M-MLV reverse transcription kit (Invitrogen, USA), according to the manufacturer's protocol. The primers CRLP-S (forward) and CRLP-A (reverse) in Table 1 were designed based on i-type lysozyme gene sequences of Crassostrea gigas and Crassostrea virginica from the National Center for Biotechnology Information (NCBI, US) and implemented using Primer 5.0 software. The RT-PCR conditions consisted of $65^{\circ} \mathrm{C}$ for $5 \mathrm{~min}$, ice cooling for $1-2 \mathrm{~min}, 37^{\circ} \mathrm{C}$ for $2 \mathrm{~min}, 25^{\circ} \mathrm{C}$ for $10 \mathrm{~min}, 37^{\circ} \mathrm{C}$ for $50 \mathrm{~min}, 70^{\circ} \mathrm{C}$ for $15 \mathrm{~min}$, stopping the reaction and then ending the program at $4{ }^{\circ} \mathrm{C}$.

The first strand cDNA was used as a template to conduct PCR amplification, with conditions as follows: initial denaturation for $3 \mathrm{~min}$ at $94^{\circ} \mathrm{C}$, followed by 30 cycles of denaturation $30 \mathrm{~s}$ at $94^{\circ} \mathrm{C}$, annealing for $40 \mathrm{~s}$ at $54^{\circ} \mathrm{C}$, extension for $40 \mathrm{~s}$ at $72^{\circ} \mathrm{C}$ and extension again for $7 \mathrm{~min}$ at $72^{\circ} \mathrm{C}$, and then finally ending the program at $4^{\circ} \mathrm{C}$. The PCR product was purified and collected using agar gel and gel extraction kit. The purified PCR product was ligated into pGM-T vector according to the instruction of the vector and then transformed into TOP10 competent E. coli using the cloning kit according to the instruction of the kit. The selected bacilli positive clones were cultured for $12 \mathrm{~h}$ and sequenced by Beijing Sunbiotech Co. Ltd .

Table. 1. Primer Sequence

\begin{tabular}{cc}
\hline Primer & Sequence $\left(5^{\prime} \rightarrow 3^{\prime}\right)$ \\
\hline CRLP-S & ATGCTCGGAGTAATGTAGTGT \\
CRLP-A & TAATGGTTGATTTCGTTCGT \\
QP-S & GAAGAACTGTCTAAAGCACCAA \\
QP-A & TAGCCGCACGAGTATGAG \\
actin-S & CATCAAGGAGATACTGGGCTA \\
actin-A & ACCGTCGGCAAGTTCATA \\
\hline
\end{tabular}

\subsection{Studies on the Expression Using Real-Time Quantitative PCR}

The primers QP-S (forward) and QP-A (reverse) in Table 1 were designed for real-time quantitative PCR (RTQ-PCR) primers according to the cloned partial conserved cDNA sequence of i-type lysozyme from $C$. hongkongensis. And the primers actin-S (forward) and actin-A (reverse) in Table 1 were designed according to $\beta$-actin gene (EU234531) [17] of $C$. hongkongensis, which was used as an endogenous reference gene (internal control). The first strand cDNA was used as a template for expression according to the instruction of Platinum $\AA^{\circledR}$ SYBR ${ }^{\circledR}$ Green qPCR SuperMix-UDG kit (Invitrogen, USA). The amplification was carried out on an ABI 7500 fast fluorescence quantitative PCR system and 40 cycles of the following were conducted: 2 $\min$ at $50^{\circ} \mathrm{C}, 2 \mathrm{~min}$ at $95^{\circ} \mathrm{C}, 15 \mathrm{~s}$ at $95^{\circ} \mathrm{C}, 30 \mathrm{~s}$ at $56^{\circ} \mathrm{C}, 30 \mathrm{~s}$ at $60^{\circ} \mathrm{C}$.

The relative gene expression of each sample was calculated using the $2^{-\Delta \Delta} \mathrm{Ct}$ method (Livak and Schmittgen, 2001). 


\subsection{Determination of the Molecular Weight and Isoelectric Point of the Protein}

The molecular weight and isoelectric point of the protein were determined using the methods of $\mathrm{Xu}$ and Ding [18], [19] as well as Ding and Xu [20].

\subsection{Statistics}

The data were analyzed using SPSS (V12.0) software. ANOVA was used to analyze the data variance and the interaction of the temperature and time. Standard error (SE) was used and marked difference was expressed using $P \leq 0.05$.

\section{Results}

\subsection{Partial cDNA Sequence of I-type Lysozyme from C. Hongkongensis}

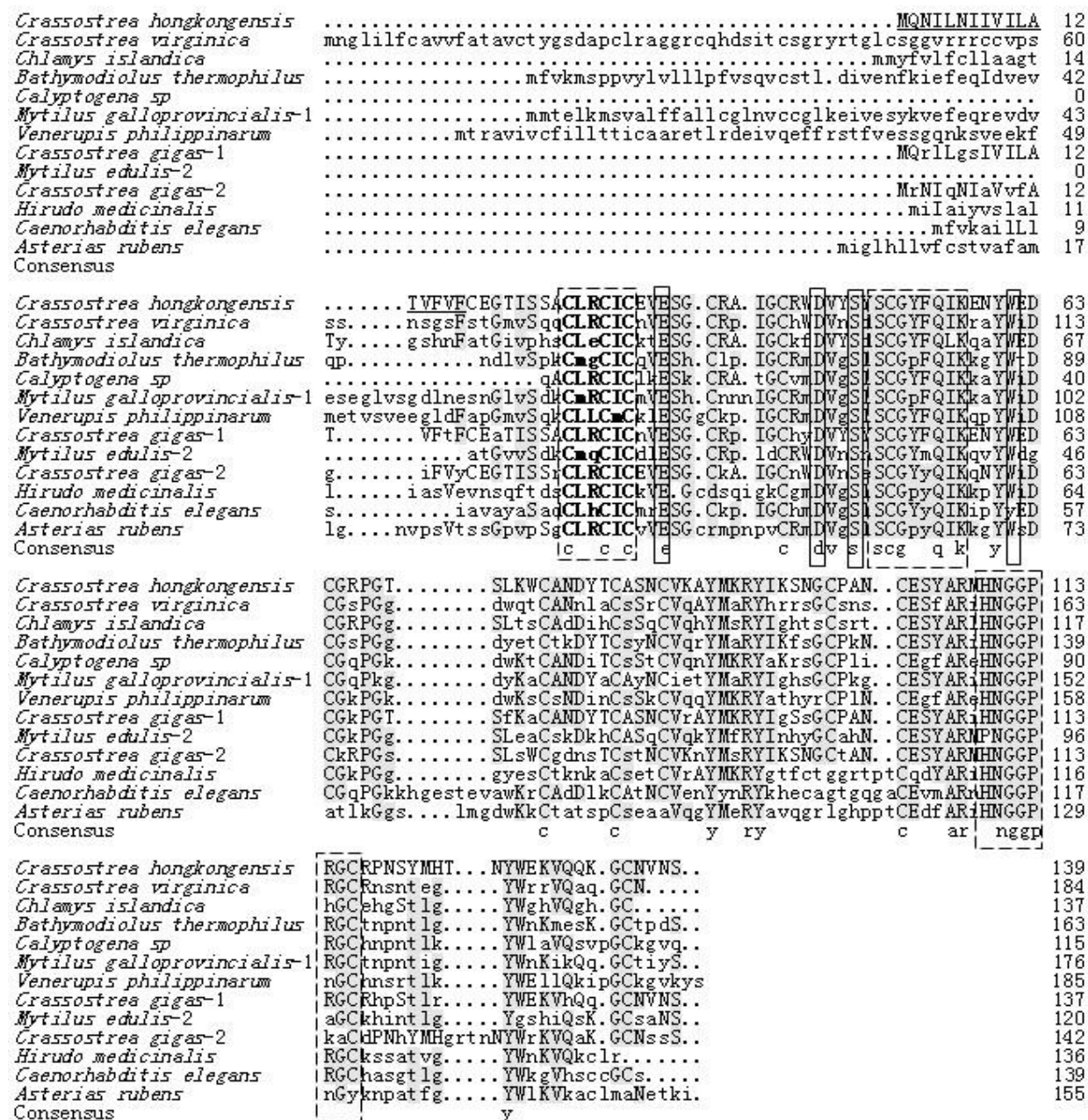

Fig. 1. Comparison of i-type lysozyme sequences among $C$. hongkongensis and other species. The signal peptide with 17 amino acid residues is underlined. The unique amino acid residue sequence of i-type lysozyme is indicated in bold font and bordered with dashed lines. A partial highly conserved sequence, SCG(P/Y)FQI, and another one, HNGGPRGC, are bordered with dashed lines. The enzyme active site with Glu, Asp, Ser and Trp is bordered with solid lines.

A 634-bp partial conserved cDNA of i-type lysozyme gene was cloned from $C$. hongkongensis. It contained a 142-bp 5'-untranslated region (5'-UTR), a 72-bp 3'-UTR and an open reading frame of $420 \mathrm{bp}$, encoding 139 amino acids. The protein sequence had the typical features of the i-type lysozyme family, containing a 
unique amino acid residue sequence, $\mathrm{CL}(\mathrm{E} / \mathrm{L} / \mathrm{R} / \mathrm{H}) \mathrm{C}(\mathrm{I} / \mathrm{M}) \mathrm{C}$ [3], a partial highly conserved sequence, SCG(P/Y)FQI [2], and the enzyme active site (Glu34, Asp45, Ser48, Trp61) [3], [21]-[23] (Fig. 1). The molecular weight of the protein was $15.77 \mathrm{KDa}$ and the isoelectric point was 8.49 , similar to the prediction using ExPASy (http://www.expasy.ch/tools/pi_tool.html) online prediction. A signal peptide with 17 amino acid residues in i-type lysozyme from $C$. hongkongensis was predicted using the online Signal P3.0 analysis (http://www.cbs.dtu.dk/services/SignalP) (Fig. 1). The partial cDNA sequence of i-type lysozyme gene from $C$. hongkongensis and its encoding amino acid sequence were deposited in the GenBank of NCBI under accession numbers JF320829 and ADY38955, respectively.

\subsection{Phylogenetic Analysis of I-type Lysozymes from C. Hongkongensis and Other Species}

A neighbor-joining (NJ) phylogenetic tree was constructed based on lysozyme types [3], [21], [24] from $C$. hongkongensis and other animals using the Clustal X (V2.0) and MEGA 4.0 softwares and the neighbor-joining (NJ) method [25]. The i-type lysozymes from $C$. hongkongensis and other species were clustered together and formed one clade within the three major branches. The i-type lysozyme from $C$. hongkongensis was the closest to those from Crassostrea gigas-1 and -2 (Fig. 2).

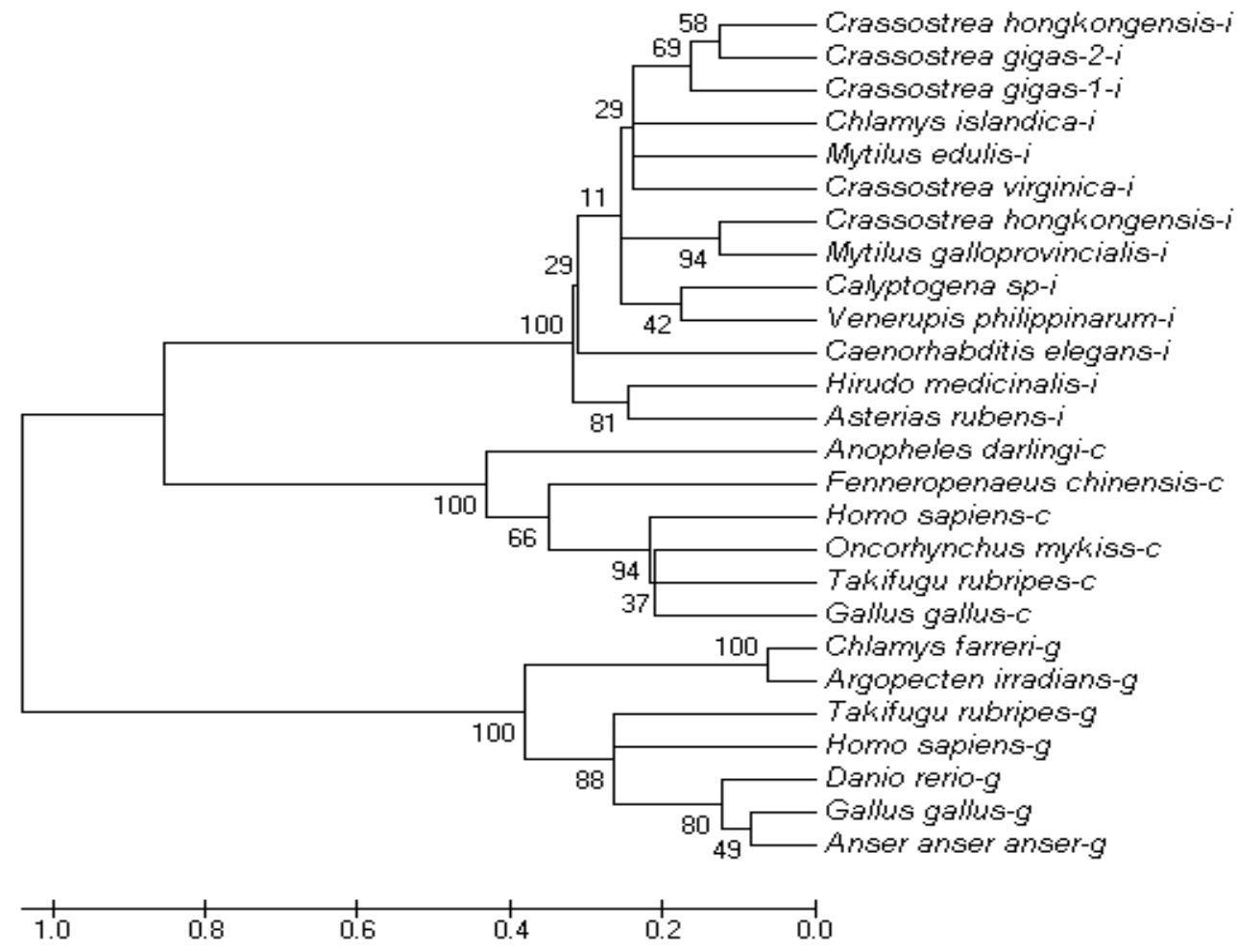

Fig. 2. Phylogenetic tree of lysozymes from $C$. hongkongensis and other species. The phylogenetic tree was constructed using the neighbor-joining (NJ) method [25]. The numbers in the tree represent the frequencies obtained after replicating for 1,000 bootstrap iterations. The scale at the lower left corner measures the tree length and represents the genetic distance.

\subsection{Comparison of I-type Lysozyme Gene Expression in Five Tissues of C. Hongkongensis}

The relative expressions of the target gene in five different tissues (digestive gland, muscle, gills, mantle and labial palps) of $C$. hongkongensis were calculated and compared their $2^{-\triangle \Delta} \mathrm{Ct}$ [26]. All expression levels 
were compared to muscle, which has been normalized to 1.0 , the expression of i-type lysozyme gene was the highest in the digestive gland based on the mean value of each tissue. The relative expression in the digestive gland is 6.70 times of that in the muscle $(P \leq 0.05)$ (Fig. 3).

\subsection{Effects of Temperature on the Expression of I-type Lysozyme Gene from. C. Hongkongensis}

The mantle of $C$. hongkongensis was used for investigation since the mantle comes into direct contact with the living environment. The RTQ-PCR results showed that the relative expression of i-type lysozyme gene in the mantle of $C$. hongkongensis varied with temperature, compared to the control group at $25^{\circ} \mathrm{C}$ (Fig. 4). Based on the mean value of $9(3 \times 3)$ samplings, the expression of i-type lysozyme gene in $C$. hongkongensis increased through day 3 and then fell rapidly to almost 0 by day 5 at $34^{\circ} \mathrm{C}$. The levels of mean expression were lower at $6^{\circ} \mathrm{C}$ as well as $13^{\circ} \mathrm{C}$. The effects of temperature and time on the mean expression of i-type lysozyme gene were significantly different $(P \leq 0.01)$. The higher temperature $\left(27^{\circ} \mathrm{C}\right.$ and $\left.34^{\circ} \mathrm{C}\right)$, the greater effect on the expression of i-type lysozyme gene before day 4 .

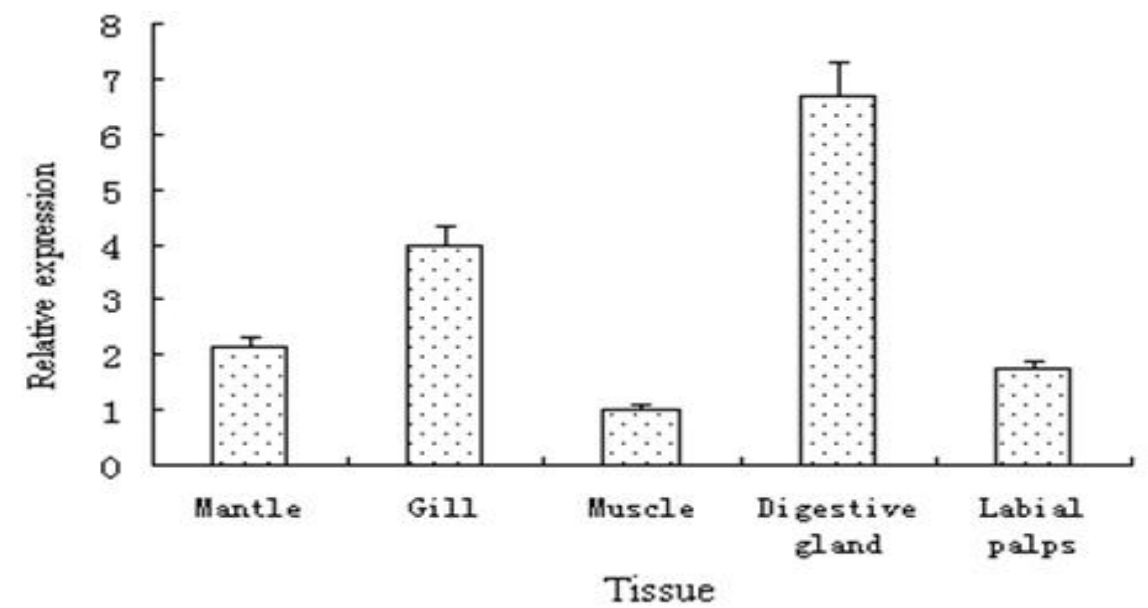

Fig. 3. Expression of i-type lysozyme in different tissues of $C$. hongkongensis at $25^{\circ} \mathrm{C}$, salinity of $15 \%$, $\mathrm{pH} 8.0$, dissolved oxygen over $5 \mathrm{mg} / \mathrm{L}(\mathrm{n}=3 \times 3, \mathrm{SE})$.

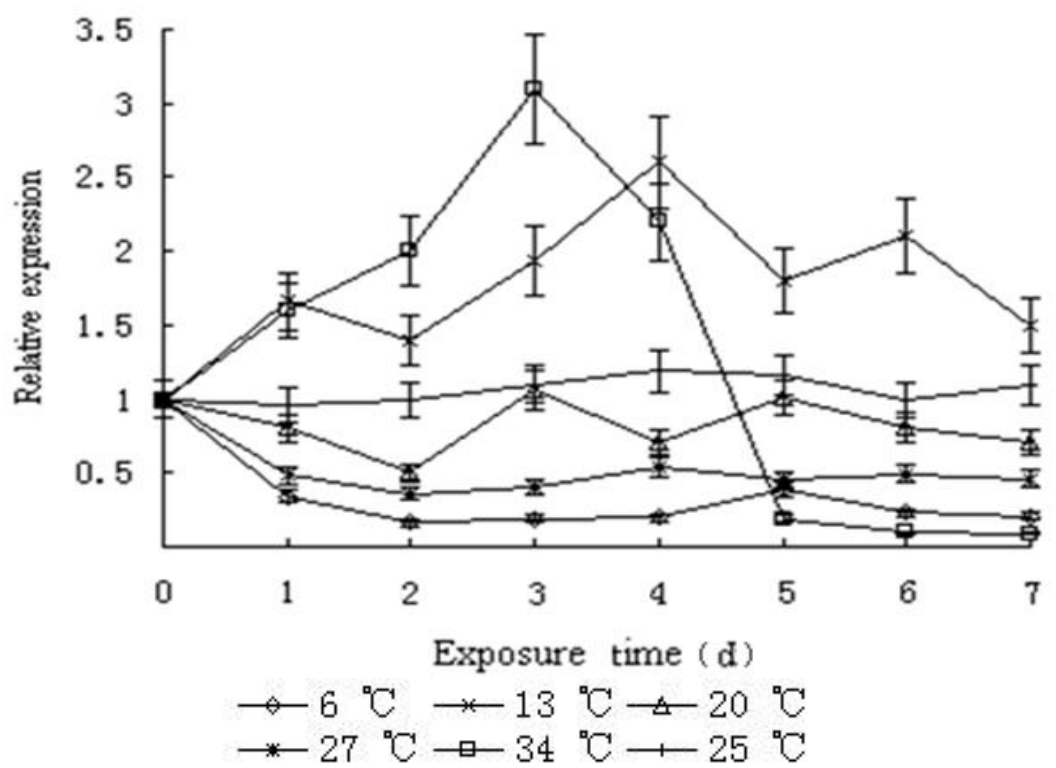

Fig. 4. Expression of i-type lysozyme from $C$. hongkongensis at different temperatures at $25^{\circ} \mathrm{C}$, salinity of $15 \%$, $\mathrm{pH} 8.0$, dissolved oxygen over $5 \mathrm{mg} / \mathrm{L}(\mathrm{n}=3 \times 3$, SE). 


\section{Discussion}

The i-type lysozyme cloned from $C$. hongkongensis had the typical characteristics of the i-type lysozyme family, including a unique amino acid residue, $\mathrm{CL}(\mathrm{E} / \mathrm{L} / \mathrm{R} / \mathrm{H}) \mathrm{C}(\mathrm{I} / \mathrm{M}) \mathrm{C}$ [3], a partial highly conserved sequence, SCG(P/Y)FQI, an enzyme active site (Glu34, Asp45, Ser48, Trp61) [3], [21]-[23], and N-terminal hydrophobic signal peptide [27]. However, another new sequence, HNGGPRGC, was discovered to exist in the i-type lysozyme of $C$. hongkongensis and the sequence was deduced to be the conserved sequence of amino acids or the evolution of $C$. hongkongensis.

Two acidic residues of amino acids, glutamate (Glu, E) and aspartic acid (Asp, D) are highly conservative in the i-type lysozyme of $C$. hongkongensis (Fig. 1). Actually, Glu and Asp are essential for the activity of any type of lysozyme [27]. However, an active site with serine (Ser, S) was found in the i-type lysozyme of Manila clam [3] and an active site with tryptophan (Trp, W) was present in the i-type lysozyme of Pacific oysters [22]. According to the sequence alignment results, other than that tryptophan (W) was replaced by tyrosine (Tyr, Y) in the i-type lysozyme of nematode, two highly conserved enzyme active sites with serine (S) and tryptophan (W) were discovered to exist in the i-type lysozyme of most invertebrates, including $C$. hongkongensis. These residues play a key role in the catalysis of cleaving the $\beta$-1,4-glycosidic bonds in the peptidoglycan of bacterial cell wall and maintaining the structural stability of the lysozyme [28]. Aspartic acid appears to participate in the formation of a covalent bond of substrate catalyzed by sugar enzyme [29].

Based on the mean relative value of each tissue, the expression of i-type lysozyme gene was found to be the highest in the digestive gland of $C$. hongkongensis, and the lowest in the muscle. Lysozyme is the most common hydrolase, which is widespread in shellfish tissues, and particularly, in the digestive gland, gonad, foot and mantle secretion [30]. Lysozyme plays an important role in the digestion and immunity of aquatic animals, especially in filter-feeding aquatic animals [4], therefore, the expression of i-type lysozyme gene was the highest in the digestive gland of $C$. hongkongensis.

In bivalves, lysozyme is synthesized in haemocytes and then secreted into haemolymph to function during phagocytosis. The activity and expression of lysozyme are susceptible to environmental factors, such as temperature [13], salinity [15], level of dissolved oxygen, food availability and pollution level. Based on the mean value of 9 ( $3 \times 3)$ samplings, the expression of i-type lysozyme gene in $C$. hongkongensis increased through day 3 and then fell rapidly to almost 0 by day 5 at $34^{\circ} \mathrm{C}$, which may be due to induce energy balance disequilibrium in C. hongkongensis. At the same time, high temperature could also cause oxidative stress and increase excessive production and accumulation of reactive oxygen species (ROS) [31], resulting in immunity reduction, cell damage, mutation, and even death [15], [32], [33]. Additionally, immune enzyme's structural stability could be affected by temperature in such a way that high temperature could change the protein's spatial structure by disintegrating the maintaining bonds and resulting in thermal denaturation [34]. A high level of temperature could also decrease the expression of genes through affecting the reactive factors, including the structural stability of RNA polymerase. Therefore, the immune function and disease-resistance of shellfish was greatly affected because of immune inhibition at high temperature of summer. In contrast, lysozyme expression was significantly reduced at $6^{\circ} \mathrm{C}$ or $13^{\circ} \mathrm{C}$. At low temperatures, various cell-level physiological functions, metabolism and gene expression declined [4].

In summary, the expression of genes can be stimulated by an appropriately high temperature. However, the expression was inhibited by overly-high or overly-low temperatures. The expression of lysozyme genes is affected by complex factors, including physiological activity, breathing, heart rate, biochemical metabolism, enzyme activity and gene expression processes [9]-[10].

\section{Acknowledgements}

Authors would like to thank for the help given by Zhezhong Pan, Wei He and Tiejun Wu of Guangxi 
Institute of Fishery Sciences. This research was financially supported by the State Support Fund for Science and Technology (2008BAD94B03), the National Natural Science Foundation of China (31360639), Guangxi Natural Science Fund (2014GXNSFAA118286, 2014GXNSFAA118292).

\section{References}

[1] Beck, G., \& Habicht, G. S. (1996). Immunity and the invertebrates. Sci Am, 275, 60-66.

[2] Bachali, S., et al. (2002). Phylogenetic analysis of invertebrate lysozymes and the evolution of lysozyme function. J Mol Evol, 54, 652-664.

[3] Zhao, J., Qiu, L., Ning, X. X., Chen, A., Wu, H., \& Li, C. (2010). Cloning and characterization of an invertebrate type lysozyme from Venerupis philippinarum. Comp Biochem Physiol B., 156, 56-60.

[4] Xu, G. C., Gu, R.B., Wen, H.B., Hua, D., \& Xie, C. (2007). Effects of environmental stress on lysozyme and superoxide dismutase of Corbicula fluminea-(Miller). J Anhui Agr Univ., 34, 74-78.

[5] Kyomuhendo, P., Myrnes, B., \& Nilsen, I. W. (2007). A cold-active salmon goose-type lysozyme with high heat tolerance. Cell Mol Life Sci., 64, 2841-2847.

[6] Pan, Y., Xie, W., \& Xia, C. (2008). Artificial induction of haploid androgenesis in the oyster, Crassostrea rivulari. J Fish Sci China, 15,172-177.

[7] Liao, W., Zhu, C., Zhang, H., Wu, J., Huang, H., \& Zhu, F. (2011). Effect of water temperature on the feeding and metabolic physiology of Crassostrea hongkongensis. Guangdong Agr Sci., 1, 7-11.

[8] Xu, Y., Cao, Z., Ding, Z., \& Gan, X. (2010). Effects of high temperature on fishes and its prevention. Aquac Sci., 29(4), 235-242.

[9] Xu, Y., Chen, Z., \& Ding, Z. (2012). Effects of low temperature on fish and its prevention. Guangdong Agr Sci., 39(15), 132-136.

[10] Xu, Y., Wu, W., Jiang, W., \& Ding, Z. (2012). Progress of studies on the effect and mechanism of temperature in the immune system of shellfish. Fish Sci (in Chinese), 31, 176-180.

[11] Kim, M., Ahn, I. Y., Cheon, J., \& Park, H. (2009). Molecular cloning and thermal stress-induced expression of a pi-class glutathione S-transferase (GST) in the Antarctic bivalve Laternula elliptica. Comp Biochem Physiol A, 152, 207-213.

[12] Liu, Z. G., Wang, H., Li, Z. M., \& Zhang, Y. L. (2007). Studies on the upper incipient lethal temperature of Argopecten irradians concentricus. J Fish Sci China, 14, 778-784.

[13] Monari, M., et al. (2007). Effects of high temperatures on functional responses of haemocytes in the clam Chamelea gallina. Fish Shellfish Immun, 22, 98-114.

[14] Yu, J. H., Song, J. H., Choi, M. C., \& Park, S. W. (2009). Effects of water temperature change on immune function in surf clams, Mactra veneriformis (Bivalvia: Mactridae). J Invertebr Pathol, 102, 30-35.

[15] Zoysa, M., Whang, I., Lee, Y., Lee, S., Lee, J. S., \& Lee, J. (2009). Transcriptional analysis of antioxidant and immune defense genes in disk abalone (Haliotis discus discus) during thermal, low-salinity and hypoxic stress. Comp Biochem Phys B, 154, 387-395.

[16] Zheng, X., Ding, Z., Xu, Y., Monroig, O., Morais, S., \& Tocher, D. (2009). Physiological roles of fatty acyl desaturases and elongases in marine fish: characterisation of cDNAs of fatty acyl $\Delta 6$ desaturase and elovl5 elongase of cobia (Rachycentron canadum). Aquaculture, 290, 122-131.

[17] Lin, Q., Liang, X. F., Wang, L., Li, G. Z., \& Hu, R. L. (2008). Cloning and analysis of the beta-actin gene in Jinjiang oyster (Crassostrea ariakensis) and other six cultivated aquatic animals. Asian J Ecotoxicol (in Chinese), 3, 256-261.

[18] Xu, Y., \& Ding, Z. (2003). Biliverdin reductase from Atlantic Salmon (Salmo Salar) Liver. Biochemistry (Moscow), 68(6), 783-787.

[19] Xu, Y., \& Ding, Z. (2004). A novel method for simultaneous purification of albumin and immunoglobin G. 
Prep Biochem Biotech, 34(4), 377-385.

[20] Ding, Z., \& Xu, Y. (2002). Purification and characterization of biliverdin Ixa from Atlantic salmon (Salmo salar). Biochemistry (Moscow), 67(8), 927-932.

[21] Itoh, N., \& Takahashi, K. G. (2007). cDNA cloning and in situ hybridization of a novel lysozyme in the Pacific oyster, Crassostrea gigas. Comp Biochem Physiol B, 148, 160-166.

[22] Itoh, N., \& Takahashi, K. G. (2009). A novel peptidoglycan recognition protein containing a goose-type lysozyme domain from the Pacific oyster, Crassostrea gigas. Mol Immunol, 46, 1768-1774.

[23] Josková, R., šilerová, M., Procházková, P., \& Martin B. (2009). Identification and cloning of an invertebrate-type lysozyme from Eisenia andrei. Develop Com Immunol, 33, 932-938.

[24] Itoh, N., Okada, Y., Takahash, K. G., \& Osada, M. (2010). Presence and characterization of multiple mantle lysozymes in the Pacific oyster, Crassostrea gigas. Fish Shellfish Immun, 29, 126-135.

[25] Saitou, N., \& Nei, M. (1987). The neighbor-joining method: A new method for reconstructing phylogenetic trees. Mol Biol Evol., 4, 406-425.

[26] Livak, K. J., \& Schmittgen T. D. (2001). Analysis of relative gene expression data using real-time quantitative PCR and the $2^{-}{ }^{\Delta \Delta C_{T}}$ method. Methods, 25, 402-408.

[27] Cong, L., Yang, X., Wang, X., Tada, M., Lu, M., Liu, H., \& Zhu, B. (2009). Characterization of an i-type lysozyme gene from the sea cucumber Stichopus japonicus, and enzymatic and nonenzymatic antimicrobial activities of its recombinant protein. J Biosci Bioeng, 107, 583-588.

[28] Kawamura, S, Ohno, K, Ohkuma, M, Chijiiwa, Y, \& Torikata, T. (2006). Experimental verification of the crucial roles of Glu73 in the catalytic activity and structural stability of goose type lysozyme. J Biochem, 140, 75-85.

[29] Vocadlo, D. J., Davies, G. J., \& Laine, R. (2001). Catalysis by hen egg-white lysozyme proceeds via a covalent intermediate. Nature, 412, 835-838.

[30] Pipe, R K. (1992). Hydrolytic enzymes associates with the granular hemocytes of the marine mussel Mytilud edulis. Histochem J, 22 ,529-603.

[31] Verlecar, X. N., Jena, K. B., Chainy, \& G. B. (2007). Biochemical markers of oxidative stress in Perna viridis exposed to mercury and temperature. Chem Biol Interact, 167, 219-226.

[32] Park, H., Ahn, I. Y., et al. (2008). Analysis of ESTs and expression of two peroxiredoxins in the thermally stressed Antarctic bivalve Laternula elliptica. Fish Shellfish Immun 25: 550-559.

[33] Wang, F. Y., et al. (2008). Effects of acute temperature or salinity stress on the immune response in sea cucumber, Apostichopus japonicus. Comp Biochem Physiol A, 151, 491-498.

[34] Dong, Z. G., Li, J. L., Li, X. Y., et al. (2005). Effects of temperature, pH and feeding on pepsin activity of Coelomactra antiquate. J Shanghai Fish Univ., 14, 397-400.

Youqing $\mathbf{X u}$ is a professor, the vice director of Fishery Sciences, Guangxi University, China. Youqing Xu's research interesting is in the fields of bioactive substances, environmental biology, nutrition, physiology, biochemistry and molecular biology of aquaqtic animals. Publication includes more than 50 SCI papers, 8 books and patents.

Zhaokun Ding is a professor, director of fishery sciences, Guangxi University, China. Zhaokun Ding's research interesting is in the fields of environmental biology, nutrition, physiology, biochemistry and molecular biology of fish. Publication includes more than 50 SCI papers, 9 books and patents.

Weiming Jiang is an associate professor of Guangxi Institute of Fishery Sciences, Nanning, China. Weiming Jiang's research interesting is in the fields of environmental biology, nutrition of aquaqtic animals. 